\title{
Experiências de monitoramento dos resultados de conferências nacionais - elementos para a discussão sobre efetividade da participação na gestão pública
}

\author{
Uriella Coelho Ribeiro \\ Universidade Federal de Minas Gerais (UFMG) \\ Joana Luiza Oliveira Alencar \\ Instituto de Pesquisa Econômica Aplicada (Ipea) \\ Paula Pompeu Fiuza Lima \\ Universidade de Brasília (UnB) \\ Clóvis Henrique Leite de Souza \\ Universidade de Brasilia (UnB) \\ Isadora Araujo Cruxên \\ Massachusetts Institute of Technology (MIT)
}

As conferências nacionais são consideradas instrumentos importantes de ampliação da participação social e das possibilidades de interação entre Estado e sociedade. Cada vez mais é frequente a realização de conferências e elas têm sido marcadas pelo envolvimento de milhares de pessoas. Embora seja crescente a sua realização, muitas questões ainda não foram respondidas sobre o que acontece após o evento e não há clareza sobre como elas impactam a gestão governamental. Diante desse panorama, este trabalho busca compreender melhor as experiências de monitoramento dos resultados das conferências: suas práticas, potencialidades e desafios. Para tanto, o artigo apresenta de forma descritiva quatro experiências investigadas: assistência social, aquicultura e pesca, mulheres e juventude. A pesquisa baseia-se em entrevistas com gestores públicos e conselheiros, bem como na análise de documentos relacionados ao monitoramento das deliberações das quatro conferências. $O$ estudo busca mapear as formas de encaminhamento das demandas apresentadas nas conferências, apontando pistas sobre questões importantes em torno da efetividade.

Palavras-chave: participação social, Estado e sociedade, políticas públicas, monitoramento, avaliação, estudo de caso

Artigo submetido em março de 2014. Versão final em dezembro de 2014. 
Experiencias de monitoreo de los resultados de la conferencias nacionales - elementos para la discusión sobre la efectividad de la participación en la gestión pública

Las conferencias nacionales son consideradas instrumentos importantes para la ampliación de la participación social y de las posibilidades de interacción entre Estado y sociedad. Cada vez es más frecuente la realización de conferencias y ellas han sido marcadas por el envolvimiento de millares de personas. A pesar de su creciente realización, muchas cuestiones aún no fueron respondidas sobre lo que sucede después del evento e no hay claridad sobre cómo ellas influencian la gestión gubernamental. En este contexto, el presente trabajo busca comprender cuales son los encaminamientos dados a los resultados de las conferencias. El objetivo es conocer mejor las experiencias de monitoreo, sus prácticas, potencialidades y desafíos. De este modo, el artículo presenta de forma descriptiva cuatro experiencias analizadas: Asistencia Social, Acuicultura y Pesca, Mujeres y Juventud. El estudio se basa en entrevistas con gestores públicos y consejeros, así como el análisis de documentos relacionados al monitoreo de las deliberaciones de las cuatro conferencias. El trabajo busca mapear las formas de encaminamiento de las demandas presentadas en las conferencias, indicando pistas sobre cuestiones importantes en torno de su efectividad.

Palabras clave: participación social, Estado y sociedad, políticas públicas, monitoreo, evaluación, estudio de caso

\section{Experiences in monitoring the results of national conferences - elements for discussion on the effectiveness of people's participation in public management}

National conferences are considered important tools to boost social participation and to allow possibilities of interaction between State and civil society. Conferences are being held more and more frequently. They have been marked by the involvement of thousands of people. Despite their increasing occurrence, many questions go unanswered about what happens after the event. It is not clear how they impact governmental conduct. Given this backdrop, this paper attempts to comprehend what kind of direction is given to conference results. The aim is to get to know better the experiences of monitoring: their practices, potentialities and challenges. Therefore, the article presents in a descriptive format four experiences investigated: Social Assistance, Aquiculture and Fishing, Women and Youth. The research relies on interviews with public supervisors and counselors, as well as on the analysis of documents related to the monitoring of the four conferences mentioned. The study attempts to map the format of the directions taken by demands presented in conferences, pointing out clues on relevant questions about their effectiveness.

Keywords: social participation, state and society, public policy, monitoring, evaluation, case study 


\section{Introdução}

As conferências nacionais são consideradas instrumentos importantes de ampliação da participação social em diferentes áreas de política pública (SouzA et al., 2013). Fazem parte de um conjunto de instituições participativas (IPs) ${ }^{1}$ cujo objetivo é ampliar as possibilidades de interação entre Estado e sociedade (PIRES; VAZ, 2012).

A partir do Governo Lula, as conferências foram fortemente incentivadas pelo Poder Executivo federal e têm sido apontadas pelos agentes políticos como parte do conjunto de IPs adotadas como método de governo. Entre 2003 e 2012, foram realizadas quase 90 conferências, que envolveram milhões de pessoas nos processos de discussão e formulação de propostas e diretrizes para as políticas públicas, desde o nível local ao nacional (IPEA, 2013a). Embora seja crescente a realização de conferências nacionais, muitas questões ainda não foram respondidas sobre o que acontece após o evento e não há clareza sobre como elas impactam a gestão governamental.

Diante desse panorama, este trabalho busca compreender quais são os encaminhamentos dados aos resultados das conferências. O objetivo é conhecer melhor as experiências de monitoramento: suas práticas, potencialidades e desafios. Para tanto, o artigo apresenta de forma descritiva as experiências investigadas. São consideradas práticas de monitoramento as tentativas de órgãos do Governo Federal (ministérios e secretarias) ou de conselhos de políticas públicas de acompanhar ações que visam atender às deliberações das conferências nacionais.

Estudar as experiências permite que sejam mapeadas as formas de encaminhamento das demandas apresentadas nas conferências. Esse mapeamento fornece pistas sobre questões importantes em torno da efetividade das conferências, uma vez que a implementação das decisões constitui uma dimensão fundamental das formas de participação ligadas às políticas públicas (AVRITZER, 2012).

A pesquisa baseia-se em entrevistas com gestores públicos e conselheiros, bem como na análise de documentos relacionados ao monitoramento das deliberações de quatro conferências: assistência social, aquicultura e pesca, mulheres e juventude. A escolha dessas políticas se baseia no fato de que existem diferenças

\footnotetext{
${ }^{1}$ Avritzer (2009) define instituições participativas como formas diferenciadas de incorporação de cidadãos e associações da sociedade civil na deliberação sobre políticas. Dentre as formas, destacam-se as experiências de orçamento participativo, conselhos gestores e de política, e conferências nacionais.
} 
entre elas quanto à necessidade de articulação com outros órgãos para executar as ações que atendam às propostas das conferências, sendo, em cada caso, exigidos arranjos para articulação e diálogo com outros órgãos, em maior ou menor grau. Entende-se que essas diferenças impactam as formas de monitoramento dos resultados das conferências.

O texto está organizado em quatro seções, além desta introdução. A primeira parte apresenta o conceito de conferência nacional, entendida como um processo do qual o monitoramento é parte. A segunda seção lança algumas considerações sobre monitoramento de deliberações de conferências e monitoramento de políticas públicas. Em seguida, são apresentadas as experiências dos quatro casos estudados, a partir de comparações entre as formas de monitoramento. Por fim, o texto traz reflexões sobre em que as práticas de monitoramento contribuem para o estudo da efetividade das conferências e das instituições participativas em geral.

\section{As conferências nacionais}

As conferências são canais institucionais de participação social, caracterizados como processos periódicos de diálogo entre Estado e sociedade a respeito de um tema. Sua realização envolve desde a convocação pelo Poder Executivo federal e o trabalho de organização e mobilização envolvido até a etapa nacional. Uma vez convocada a conferência, constitui-se uma comissão organizadora nacional. Em seguida, os Poderes Executivos municipais e estaduais convocam as etapas locais e formam-se as comissões organizadoras estaduais e municipais, que são responsáveis pela realização de cada etapa.

Em cada etapa, são elaboradas propostas e eleitos representantes governamentais e não governamentais que seguem à etapa seguinte. Assim, propostas elaboradas nas etapas municipais são discutidas na etapa estadual por delegados eleitos nas etapas municipais. O mesmo ocorre quando se passa das etapas estaduais para a etapa nacional. Apesar de a fase final abordar as demandas vindas das etapas preparatórias, algumas conferências permitem que novas propostas sejam elaboradas na etapa nacional (SouzA et al., 2013).

Os resultados da conferência são encaminhados para os responsáveis pela organização da conferência, para serem organizados em um relatório final ou como listagem de demandas consolidadas como propostas. A Figura 1 retrata a "realização" da conferência.

As conferências são, em geral, realizadas para a formulação de propostas de políticas públicas, mas também costumam ter como objetivos a avaliação de ações e realidades, o fortalecimento da participação e a afirmação de ideias e 
compromissos. Segundo classificação dos objetivos das conferências proposta por Souza (2012) - agendamento, avaliação, participação e proposição² -, percebese que 92\% das 69 conferências típicas ${ }^{3}$ realizadas entre 2003 e 2011 indicaram proposição como objetivo, enquanto $56 \%$ apontaram agendamento, 56\% incluíram avaliação e $47 \%$ dos processos manifestaram o fortalecimento da participação também como objetivo (IPEA, 2013a).

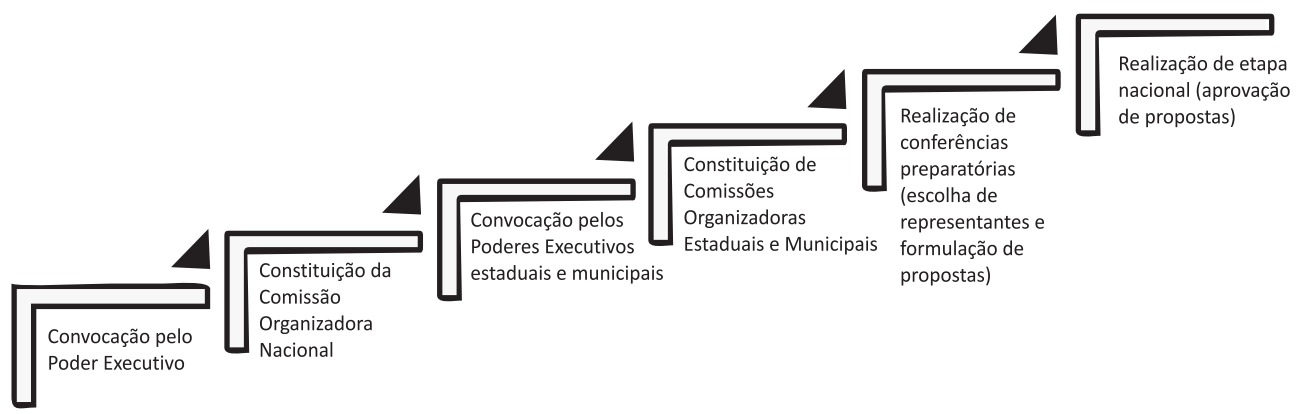

Fonte: Souza et al. (2013)

Figura 1: Etapa "realização" do processo conferencial

Os resultados das conferências podem variar de acordo com os objetivos propostos. Algumas conferências, por exemplo, têm como resultado a criação ou reformulação e avaliação de um plano nacional de política, consolidado em eixos temáticos, diretrizes e objetivos. Em outros casos, a conferência se organiza em torno da estruturação ou avaliação de um sistema de política existente. Podemse gerar relatórios-síntese sobre o que foi debatido nas conferências ou apenas a transcrição das deliberações resultantes das conferências, sem nenhuma

\footnotetext{
${ }^{2}$ Os objetivos foram considerados de agendamento quando se referiam à difusão de ideias e à afirmação de compromissos. De avaliação, quando estavam em foco ações de diagnóstico de uma situação ou avaliação de políticas, inclusive apreciação do encaminhamento de deliberações de conferências. Os objetivos foram considerados de participação quando falaram em ampliação ou fortalecimento de espaços participativos na gestão de políticas públicas. Por fim, foram considerados de proposição quando traziam aspectos de formulação de estratégias ou políticas para garantia de direitos, articulação entre entes federados e financiamento de ações, identificação de prioridades de ação para órgãos governamentais, além de intenções específicas de criação ou reformulação de planos, programas, políticas e sistemas (IPEA, 2013a).

${ }^{3}$ De acordo com pesquisa do Ipea (2013), são consideradas conferências típicas as que se constituem como processos de promoção do diálogo entre governo e sociedade. Convocadas pelo Executivo, realizam etapas preparatórias, em uma estrutura escalonada, marcadas pelo encaminhamento de propostas e pela seleção de representantes - tanto do governo como da sociedade - para as etapas seguintes. As conferências que não apresentam algumas das características comuns à maioria delas são consideradas como atípicas.
} 
organização em formato de texto final. Em outros casos, foram criadas instituições de participação para apoiar a temática, seja um conselho ou comitês temáticos.

Olhar para os períodos entre as edições das conferências permite perceber atores e trabalhos em movimento, dentro de um ciclo que se inicia com a organização da conferência, quando atores e recursos são mobilizados para o planejamento e execução desde a etapa municipal até o encontro nacional. Daí resulta um documento que contém as propostas finais aprovadas na conferência, chamadas também de output participativo. Em seguida, espera-se que ocorra o encaminhamento dessas propostas pelos setores responsáveis por cada uma das demandas, o que pode envolver formulação, aprimoramento, implementação e monitoramento de políticas.

Do mesmo modo, é esperado que o governo acione ou crie mecanismos de accountability como forma de prestar contas à sociedade com informações sobre os encaminhamentos dados aos resultados pactuados na conferência. Completando o ciclo e como forma de se organizar para a conferência seguinte, há o controle e o acompanhamento por parte da sociedade, ou seja, o controle social.

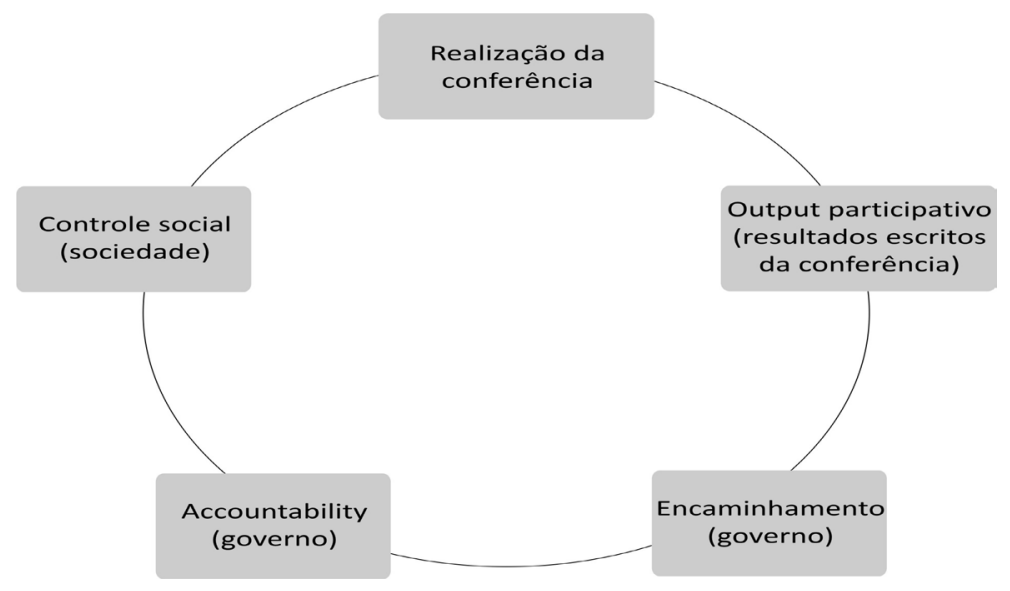

Fonte: Elaboração própria dos autores.

\section{Figura 2: Modelo circular de funcionamento das conferências nacionais}

A ideia do ciclo não é necessariamente marcar uma sequência temporal, mas sim destacar momentos-chave no processo conferencial. Esse formato visa salientar o fato de que as conferências não são apenas eventos, mas processos de diálogo e interação entre governo e sociedade marcados por diferentes etapas.

O monitoramento de resultados de conferências está presente quando o conselho ou o órgão governamental diretamente ligado à realização da conferência 
faz a observação sistemática do encaminhamento das propostas, de modo a criar condições para a prestação de contas por parte do governo - quando feito pela secretaria ou ministério - e tornar possível o diálogo e controle social pela sociedade - especialmente quando feito pelo conselho. A próxima seção traz considerações sobre o monitoramento, etapa fundamental para se pensar a efetividade das conferências, tema central deste artigo.

\section{O monitoramento de políticas e o monitoramento pós-conferência}

O monitoramento pós-conferência ou das deliberações de conferências consiste no acompanhamento das demandas e propostas construídas durante o processo conferencial, dirigidas a uma área de política pública predeterminada. Esse tipo de ação é uma prática recente. Embora semelhante ao monitoramento de programas e projetos de políticas públicas em alguns aspectos, existem peculiaridades específicas ao processo das conferências.

No que se refere às políticas públicas, assim como aos programas e projetos vinculados a elas, o País vivenciou um momento rico em relação às técnicas, discussões teóricas e políticas sobre monitoramento e avaliação nos últimos quarenta anos. Esse processo foi marcado pela colaboração de instituições públicas e privadas, assim como universidades e pela inserção da avaliação nos processos de tomada de decisão e formulação de políticas públicas (GASPARINI, 2014).

As atividades de monitoramento e avaliação de políticas têm por objetivo estreitar a relação entre o que é planejado para a política pública e o que de fato acontece na realidade. Embora monitoramento e avaliação estejam estreitamente relacionados, consistem em procedimentos diferentes.

Monitoramento é um processo contínuo e permanente de análise, observação e sugestões de ajuste. Ele se dá durante a execução da política, deve ser um procedimento sistemático utilizado para identificar aspectos frágeis, de modo a aperfeiçoar os processos e melhorar os resultados. Assim, indica o progresso alcançado na execução da política, incluindo estrutura, custos, prazos, e deve ser efetuado em tempo de se executarem ações corretivas. Nesse processo, os gestores têm a responsabilidade de corrigir os problemas encontrados, fazendo os ajustes necessários às condições para alcance dos objetivos da política (ORTEGón et al., 2005).

A avaliação deve trazer considerações acerca do que se observa em pontos específicos do projeto, avaliar se os objetivos foram atingidos de acordo com o planejamento, e apontar modificações necessárias ao desenho inicial. Essa avaliação é feita a partir das informações obtidas no monitoramento (ORTEGón et al., 2005; COTTA, 1998). 
Para avaliar e monitorar programas, é necessário eleger critérios e construir indicadores que permitam acompanhar as mudanças de resultados ao longo do tempo, comparando os desempenhos anteriormente alcançados. É importante que o monitoramento seja contínuo e a avaliação sistemática, para aperfeiçoar o desempenho das políticas públicas, tornando-as mais eficazes e permitindo a reformulação em direção a desenhos mais consistentes (COSTA; CASTANHAR, 2003).

O monitoramento de deliberações de conferências trata do acompanhamento de propostas construídas num espaço de participação da sociedade, que podem, por sua vez, ser ou não acatadas pelos governantes. Ele permite verificar qual encaminhamento tem sido dado pelo governo às demandas das conferências e se essas têm influenciado as políticas públicas, como a maior parte se propõe a fazer. Diferencia-se do monitoramento de políticas públicas na medida em que observa o impacto das conferências na gestão pública, enquanto o segundo visa analisar o impacto sobre a população-alvo ou um contexto específico.

Um ponto de partida para o monitoramento das deliberações de conferências é o relatório final, que normalmente contém todas as demandas e propostas (deliberações da conferência). Uma das ações necessárias ao monitoramento é a verificação do primeiro encaminhamento dado aos resultados da conferência, se foram utilizados para constituir planos, se foram encaminhados a todos os possíveis responsáveis nos diversos setores, se geraram políticas, ou se não tiveram encaminhamento.

É importante destacar que a definição prévia do que se espera como resultado da conferência - por meio de ato convocatório, regimento ou regulamento - influencia a viabilidade e a qualidade do monitoramento. Quando se sabe qual é a finalidade explícita da conferência, maiores são as chances de os participantes conseguirem monitorar. Se não há clareza quanto ao objetivo e ele é definido posteriormente pelo governo, sem pactuação com a população, isso gera dificuldade para o monitoramento, podendo comprometer o processo democrático.

O grupo responsável pelo monitoramento pós-conferência - seja ele formado pelo governo, pela sociedade ou por ambos - precisará lidar muitas vezes com uma quantidade grande de demandas que, apesar de versarem sobre uma temática afim, podem não ser de competência de um único órgão, porque a natureza das demandas é bastante variada. É necessário verificar para quais órgãos as propostas precisam ser encaminhadas e acompanhar se elas foram de fato para os órgãos e setores potencialmente responsáveis por sua execução. Após esse primeiro processo, torna-se possível verificar os desdobramentos das demandas.

As propostas podem ser acatadas ou não. Elas são selecionadas e encaminhadas de acordo com os critérios de cada órgão responsável. Logo após, começa o 
acompanhamento junto aos setores responsáveis, que devem prestar informações frequentes sobre os programas relacionados às demandas que thes competem. Esses podem constituir programas que existiam antes da conferência ou que passaram a existir como fruto das deliberações. A partir daí, passa-se a acompanhar os indicadores das políticas públicas associadas ao atendimento das demandas. Os indicadores são elementos fundamentais para tornar o monitoramento mais objetivo e exequível. No entanto, a produção de indicadores para muitas políticas ainda precisa ser aperfeiçoada, em especial quando se faz necessário analisar as políticas de forma qualitativa.

A próxima seção apresenta as experiências estudadas e destaca as potencialidades vivenciadas, os principais desafios e as lições aprendidas.

\section{Quatro experiências de monitoramento}

Esta seção apresentará as quatro experiências de monitoramento selecionadas: políticas para as mulheres, juventude, assistência social, aquicultura e pesca. As informações apresentadas têm por base entrevistas e análise de documentos, coletados no primeiro semestre de 2013, durante a pesquisa "Experiências de Monitoramento de Resultados de Conferências" (IPEA, 2013b). Este artigo apresenta informações de entrevistas realizadas com 10 envolvidos diretos com os mecanismos de monitoramento ${ }^{4}$. As entrevistas foram guiadas por um roteiro semiestruturado com questões sobre as experiências de monitoramento: os atores envolvidos, as relações entre a organização e realização das conferências com as práticas de monitoramento, os instrumentos criados, as ações realizadas e os resultados positivos, e os principais desafios. Para auxiliar a análise das informações obtidas pelas falas dos gestores, foram consultados os documentos de regulamentação e organização das conferências (decreto de convocação, manuais de organização, regimento interno), seus relatórios finais e os sites e documentos relacionados ao monitoramento, como planilhas e relatórios.

Um dos esforços empreendidos foi o de identificar nos documentos e nas falas dos entrevistados as diferentes ações que compõem a prática do monitoramento. Acredita-se que a forma como os gestores narram as ações expressa visões a respeito

\footnotetext{
${ }_{4}^{4}$ Para este artigo, foram entrevistadas três gestoras envolvidas com o monitoramento do Plano Nacional de Políticas para as Mulheres (PNPM); um conselheiro envolvido com o monitoramento das deliberações da conferência de aquicultura e pesca; dois gestores que atuam no monitoramento da juventude; um gestor ligado ao monitoramento da assistência social. Para a realização da pesquisa, o planejamento previa apenas uma entrevista. Porém, nos casos em que existiu a necessidade de complementar a primeira entrevista, outra pessoa foi entrevistada.
} 
das práticas e revela iniciativas que visam garantir a efetividade das conferências, seus principais obstáculos e aprendizados. O trabalho identifica potencialidades e desafios relacionados às práticas de monitoramento, trazendo, dessa forma, algumas pistas sobre a efetividade da participação na gestão pública.

A análise neste trabalho é feita com base na descrição dos diferentes arranjos constituídos para realizar o monitoramento de deliberações de conferências. São destacadas: as instâncias que realizam o monitoramento, a existência ou não de articulações entre órgãos e outras instâncias, as formas e intensidades das ações governamentais e da sociedade, e os entendimentos sobre o que deve ser feito para garantir o encaminhamento das deliberações.

\section{Conferência Nacional de Políticas para Mulheres}

Em 2004, foi realizada a I Conferência Nacional de Políticas para as Mulheres (I CNPM), que, desde então, teve mais duas edições (2007 e 2011), todas organizadas pela Secretaria de Políticas para as Mulheres da Presidência da República (SPM-PR), com o apoio do Conselho Nacional dos Direitos da Mulher (CNDM).

As conferências nacionais de políticas para mulheres aprovam diretrizes, transcritas no relatório final, que servem de base para o Plano Nacional de Políticas para as Mulheres (PNPM), elaborado pela SPM em parceria com o Comitê de Monitoramento do PNPM. O primeiro plano corresponde às deliberações da primeira conferência. Os demais são, ao mesmo tempo, reflexos das conferências e adequações do PNPM para o período correspondente. Para as adequações, as segunda e terceira edições das conferências adotaram como texto-base de discussão o PNPM do período em vigor. Desse modo, são contempladas demandas que ainda não foram respondidas e novas demandas surgidas durante as conferências, respeitando o que é prioritário, realizando ajustes, traduções e sistematizações das demandas.

O processo de "tradução" do relatório final em um plano de política não está descolado do processo participativo das conferências. A equipe de elaboração do PNPM tem mantido conexões e preocupações com o que as conferências demandam. Um dos exemplos é a manutenção do "Capítulo 9 - Enfrentamento do racismo, sexismo e lesbofobia", um capítulo controverso dentro do governo. Como a manutenção do capítulo foi uma exigência da terceira edição da conferência, o governo manteve o capítulo no PNPM referente ao período 2013-2015.

Todo esse processo da conferência de mulheres aponta questões interessantes sobre a efetividade, porque é notória a preocupação em inserir o que é debatido e decidido na conferência dentro do planejamento, aos transformar o relatório final em um plano de política, questão já predefinida nos objetivos da conferência em Regimento Interno. Além disso, esse processo toma mais corpo quando ele é organizado de forma contínua e não fragmentada, sendo a elaboração do PNPM do próximo período baseada no planejamento do período anterior. 
Porém, a inserção no planejamento não garante, necessariamente, que as propostas serão executadas. No caso das políticas para as mulheres, isso ocorre especialmente porque as políticas de gênero são transversais e sua efetiva implementação depende da colaboração de várias instâncias, pois não cabe à SPM a função de executar diretamente as demandas. Esse processo é marcado por negociações entre a SPM e demais órgãos, visando promover ações específicas para as mulheres e otimizar as ações consideradas universais relacionadas às condições de vida das mulheres. Essas negociações, portanto, respaldam as ações do PNPM junto aos órgãos executores das políticas.

A elaboração, reformulação e aprimoramento dos planos também implicam o objetivo de tornar os órgãos executores - que são os diversos ministérios envolvidos na implementação de diretrizes resultantes da conferência de mulheres - permeáveis às demandas, sendo esses órgãos chamados para participar de debates e realização de parcerias.

Nesse sentido, foi criado, por decreto presidencial, o Comitê de Articulação e Monitoramento do Plano Nacional de Políticas para as Mulheres com o objetivo de acompanhar o desenvolvimento das ações do plano por cada um dos diferentes órgãos do Governo Federal, fazendo com que conceitos e práticas que atendam às necessidades específicas das mulheres sejam incorporados às políticas governamentais de todas as áreas e nas diversas instâncias e fóruns governamentais e não governamentais. Em 2005, o comitê era composto por 12 ministérios e três representações do Conselho Nacional dos Direitos da Mulher (Decreto no 5.390 de 2005). Os Decretos no 5.446, de 20 de maio de 2005; no 5.390, de 8 de março de 2005; no 6.269, de 22 de novembro de 2007; e no 6.572, de 17 de setembro de 2008, deram nova redação ao inciso IV do art. 4으 do Decreto no 5.390, acrescentando dez novos membros ao comitê.

Atualmente, ele é composto por 32 ministérios e órgãos que têm ações em comum com a SPM, de acordo com o Decreto no 7.959, de 13 de março de 2013. Desse modo, a formulação, implementação e avaliação do PNPM conta com o envolvimento direto de 32 órgãos governamentais. Além disso, o comitê trabalha para introduzir a perspectiva de gênero nos órgãos federais, estimulando e dando suporte à criação de mecanismos de gênero ${ }^{5}$ nesses órgãos. Em 2014, existem 11 órgãos do Poder Executivo federal com mecanismos de gênero.

\footnotetext{
${ }^{5}$ Mecanismo de gênero é um espaço para a inserção da perspectiva de gênero nos órgãos governamentais, é uma forma de articulação para a elaboração de políticas para a igualdade de gênero. O mecanismo pode ser uma assessoria do ministro especializada em gênero, uma diretoria, ou uma coordenadoria. A proposta da SPM é a criação de um Comitê de Gênero em cada órgão do Governo Federal. Para mais informações, acessar http://spm. gov.br/pnpm/48a-reuniao/palestra-1-por-que-criar-mecanismos-de-genero-nos-orgaos-governamentais.pdf.
} 
O Conselho Nacional dos Direitos das Mulheres participa do comitê e tem, na sua estrutura organizacional, uma câmara responsável pelo acompanhamento do PNPM, e outra de orçamento e planejamento. Essas comissões monitoram os relatórios apresentados pela SPM e a execução orçamentária relativa a ações voltadas para os direitos das mulheres. Além disso, elegem prioridades para monitoramento mais aprofundado.

Junto ao comitê funciona o Sistema de Acompanhamento do PNPM, criado pela SPM. Ele funciona on-line, disponibilizando formulários virtuais que devem ser preenchidos pelos gestores responsáveis pela implementação dos projetos. Nesses formulários, para cada ação do PNPM, os gestores devem inserir informações que destacam desde o produto e resultados esperados, até o que foi alcançado. As duas primeiras colunas tratam das expectativas e a terceira denomina o órgão responsável pelas ações traçadas. As quarta e quinta colunas identificam os resultados obtidos e o programa vinculado ao PPA de referência da ação, respectivamente. As duas últimas colunas detalham os resultados a partir da explicitação do valor liquidado e de uma descrição do que foi alcançado. As ações são divididas por objetivos específicos e eixos temáticos ${ }^{6}$. A planilha utilizada pelo comitê pode ser visualizada no Quadro 1.

Quadro 1: Planilha do sistema de acompanhamento do PNPM

\begin{tabular}{|c|c|c|c|c|c|c|}
\hline $\begin{array}{c}\text { Ação } \\
\text { Proposta }\end{array}$ & Produto & $\begin{array}{c}\text { Órgão } \\
\text { competente }\end{array}$ & Resultado & $\begin{array}{c}\text { Programa/ } \\
\text { Ação PPA }\end{array}$ & $\begin{array}{c}\text { Valor } \\
\text { Liquidado }\end{array}$ & $\begin{array}{c}\text { Descrição } \\
\text { dos } \\
\text { resultados }\end{array}$ \\
\hline $\begin{array}{c}\text { Texto da ação } \\
\text { proposta } \\
\text { aprovada em } \\
\text { conferência e } \\
\text { incorporada } \\
\text { no PNPM }\end{array}$ & $\begin{array}{c}\text { Produto } \\
\text { esperado }\end{array}$ & $\begin{array}{c}\text { Esfera de } \\
\text { competência - } \\
\text { ministério ou } \\
\text { outros órgãos }\end{array}$ & $\begin{array}{c}\text { Resultado } \\
\text { obtido (em } \\
\text { números) }\end{array}$ & $\begin{array}{c}\text { Número do } \\
\text { programa } \\
\text { ou ação } \\
\text { do PPA de } \\
\text { referência }\end{array}$ & $\begin{array}{c}\text { A execução } \\
\text { orçamentária }\end{array}$ & $\begin{array}{c}\text { Descrição } \\
\text { sucinta dos } \\
\text { resultados } \\
\text { alcançados }\end{array}$ \\
\hline
\end{tabular}

Fonte: Ipea (2013b).

\section{Conferência Nacional de Juventude}

A primeira conferência convocada pela Secretaria Nacional de Juventude (SNJ) e pelo Conselho Nacional de Juventude (Conjuve) foi realizada em 2008, e nela foram aprovadas 70 resoluções. Não havia nenhum plano de acompanhamento sistemático da conferência. As atividades desenvolvidas após essa primeira conferência concentraram-se em duas prioridades: 1) transformação das resoluções do "1o

\footnotetext{
${ }^{6}$ É possível ter acesso aos relatórios públicos por meio do site: http://www.sigspm.spmulheres.gov.br/relatorios.php.
} 
Encontro Nacional de Juventude Negra (Enjune) sobre os Direitos da Juventude Negra e Fortalecimento Institucional" em políticas públicas de juventude, e 2) aprovação, pelo Congresso Nacional, do marco legal da juventude ${ }^{7}$. Nesse sentido, foram realizados, pelo Conjuve e pela SNJ, debates, oficinas, reuniões com ministérios e com o Congresso Nacional.

Após a segunda conferência, o Conjuve começou a pesquisar formas de construir uma matriz de monitoramento das políticas públicas de juventude. A SNJ e o conselho consideram haver uma relação estreita entre as resoluções de conferências e as políticas de juventude. Ambas as conferências tiveram como objetivo declarado a construção e o fortalecimento da política nacional da juventude. Dessa forma, existe o entendimento de que monitorar as políticas de juventude é bem próximo de monitorar os resultados de conferências.

Um dos objetivos da SNJ é criar indicadores que apontem os impactos das políticas públicas tanto de forma quantitativa quanto qualitativa, por meio de estatísticas que tragam a dimensão da quantidade de jovens que estão incluídos e permanecem nas políticas avaliadas, mas também apontem os impactos do programa em cada comunidade. Nesse sentido, o Conjuve e a SNJ exercem, separadamente ou em conjunto, atividades de monitoramento de resultados de conferências, que podem ser consideradas incipientes. O conselho possui uma comissão permanente de acompanhamento das políticas e programas de juventude cuja finalidade é avaliar as políticas do Governo Federal que afetam a juventude. A comissão existe na estrutura do Conjuve desde 2006 e tem seu foco de atuação definido pelo plenário do conselho.

ASNJ, por sua vez, realiza a articulação com outros ministérios. Conformeé possível perceber por meio do trabalho já realizado pela comissão de acompanhamento, a política de juventude é transversal, assim como a das mulheres. Isso faz com que o monitoramento de deliberações de conferências tenha que ser feito por meio da construção de uma rede que colabore na produção e disponibilização das informações relativas à distribuição, ao andamento, e ao acompanhamento das deliberações de conferências e políticas a elas relacionadas. Por esse motivo, a SNJ tem como objetivo constituir um comitê interministerial permanente para institucionalizar a relação com os ministérios envolvidos na temática da juventude.

Assim, percebe-se que a área de juventude ainda possui trabalhos incipientes na atividade de monitorar as deliberações de conferências. Isso porque está concentrada em consolidar as políticas públicas de sua área e estabelecer

\footnotetext{
${ }^{7}$ Regime de urgência da PEC no 138/2003, Plano Nacional de Juventude, PL no 4530/2004 e Estatuto dos Direitos da Juventude, PL no 27/2007.
} 
mecanismos para monitorar essas políticas. O acompanhamento das decisões de espaços participativos é entendido como necessário, mas se entende também que deve ser feito de forma integrada com o das políticas públicas em si.

\section{Conferência Nacional de Assistência Social}

A I Conferência Nacional de Assistência Social ocorreu em 1995 e, até 2013, nove edições já foram realizadas. Em 2003, na IV Conferência, foi deliberada a criação do Sistema Único de Assistência Social (SUAS). A partir desse marco, foram construídos diferentes instrumentos de gestão desse sistema. Em 2004, foi aprovada a Política Nacional de Assistência Social, que aponta diretrizes e princípios para a ação estatal, em parceria com atores da sociedade, de proteção de sujeitos em situação de vulnerabilidade social. Em 2005 e 2006, foram aprovadas pelo Conselho Nacional de Assistência Social (CNAS) as Normas Operacionais Básicas relacionadas à estruturação do SUAS.

Em 2011, a Lei Orgânica da Assistência Social (LOAS) foi revisada, incorporando a discussão sobre o SUAS. Por fim, ocorreu a revisão da Norma Operacional Básica (NOB/SUAS) no CNAS, na qual consta que o conselho deverá encaminhar as deliberações da conferência aos órgãos competentes após sua realização e desenvolver metodologias de acompanhamento e monitoramento das propostas aprovadas, institucionalizando, assim, o papel do conselho como responsável pelo encaminhamento e monitoramento das deliberações das conferências.

Embora o acompanhamento das propostas seja responsabilidade do CNAS desde 2012, antes dessa data o conselho já desenvolvia diferentes iniciativas de monitoramento. É possível identificar esses esforços a partir da III Conferência. Em 2002, em parceria com os conselhos estaduais e do Distrito Federal, o CNAS elaborou o plano de execução das deliberações da III Conferência. Nele, foram priorizadas deliberações e traçadas estratégias que contribuiriam para o atendimento das demandas.

Foram identificados os responsáveis pela execução de cada estratégia, que, na maioria das vezes, eram os próprios conselhos ou organizações presentes no conselho. Além disso, foi registrado qual era o prazo necessário para a implementação das estratégias, classificando-as como de curto, médio e longo prazo.

Em 2003, quando o CNAS elaborou seu planejamento estratégico, foi declarada a intenção de monitorar as deliberações da IV Conferência. Não havia ainda uma ação com metodologia definida, mas foi considerada a necessidade de priorizar ações para executar as propostas. Em 2006, em preparação para a V Conferência, foi realizado um levantamento das propostas aprovadas desde a I Conferência, as quais foram comparadas com as resoluções do CNAS, buscando identificar se as ações do conselho atendiam às diretrizes oriundas das conferências. 
Essa sistematização foi feita com base na identificação de "ideias-força" que indicavam quais eram as principais demandas apresentadas por meio das deliberações. Foram também mapeados responsáveis pela implementação de cada demanda e as ações, programas e atos normativos aos quais essas deliberações se referiam, quando se referiam a alguma política específica. Além disso, foram sistematizados os assuntos dos grupos de trabalho criados pelo CNAS, a fim de relacioná-los aos assuntos deliberados nas conferências nacionais.

A V Conferência construiu o Plano Decenal - plano de metas para implementação da Política Nacional de Assistência Social para os 10 anos seguintes. A discussão sobre o Plano Decenal continuou na VI Conferência, que avaliou e consolidou o trabalho anterior. Nessa conferência, foram aprovadas metas nacionais e as estratégias necessárias para alcançá-las. Enquanto a V Conferência teve um caráter de elaboração conceitual do plano e de pactuação de compromissos que norteiam a Política de Assistência Social, a VI Conferência aprofundou as metas já estabelecidas na V, definindo as estratégias que melhor contribuiriam para o cumprimento das metas.

Entre a VII e a VIII conferências, não houve novidades na questão do monitoramento. Um ano após a VIII, foi montado um grupo de trabalho integrado por representantes de cada comissão do conselho para monitorar as ações desenvolvidas a partir das deliberações de conferências referentes a cada área. Além disso, a comissão organizadora da IX Conferência orientou as comissões municipais a retomarem as deliberações das conferências anteriores como parte do processo de preparação das conferências municipais. Essa orientação tinha como propósito servir de subsídio para o debate que ocorreria na etapa nacional, que incorporou em sua metodologia a classificação das propostas entre novas e recorrentes. As propostas que já tinham sido feitas em conferências anteriores e ainda não tinham sido implementadas seriam aprovadas automaticamente, já fazendo parte do relatório final. A ideia era reafirmar deliberações ainda pendentes e priorizar a discussão de novas propostas.

A experiência de monitoramento na área de assistência social se concentrou em iniciativas do próprio conselho, sendo que o ministério se responsabilizou, em especial, no momento do Plano Decenal. A principal dificuldade nesse processo de acompanhamento dos resultados da conferência foi a inexistência de uma metodologia sistemática. Esse caso, apesar de mais antigo em relação aos demais, passa neste momento por uma etapa de amadurecimento. As experiências foram diversas e em número maior que as de outras áreas, porém desconectadas. Hoje o conselho reconhece a necessidade de construir o monitoramento de forma mais sistemática e planejada e trabalha nesse sentido. 


\section{Conferência Nacional de Aquicultura e Pesca}

A 1aㅡ Conferência de Aquicultura e Pesca, em 2003, teve como foco o fortalecimento do tema na agenda do Governo Federal e gerou um documento de resoluções, que contém indicadores, estratégias e metas. Uma dessas estratégias, documentada como objetivo da conferência, foi instalar e fazer funcionar o Conselho Nacional de Aquicultura e Pesca (Conape), que foi criado no ano seguinte. A 2a Conferência foi feita a partir de um texto proposto pela comissão organizadora da conferência e teve como resultado um conjunto de emendas a esse texto. Entre suas deliberações, estava a centralização das responsabilidades relativas à temática - fomento, ordenamento, fiscalização, pesquisa e estatística - num único órgão. Além disso, determinou a criação do Ministério de Pesca e Aquicultura (MPA) e a extinção da secretaria especial, o que só acontece após a terceira conferência, em 2009.

A experiência de monitoramento de deliberações de conferências na área de aquicultura e pesca iniciou-se em 2010, pós a realização da 3á Conferência. O monitoramento é feito pelo Conselho Nacional de Aquicultura e Pesca (Conape), por meio do comitê permanente de acompanhamento e cumprimento das conferências. As funções do comitê são: promover estudos, comparações e análises, a partir dos documentos finais das conferências, do diálogo com os diferentes setores do ministério da pesca e das ações deliberadas, em fase de implementação ou concluídas. A partir desses estudos deve ser elaborada uma síntese, que é apresentada à plenária em todas as reuniões ordinárias do conselho.

As deliberações das conferências de pesca requerem, em sua maior parte, ações que podem ser executadas basicamente pelo MPA. Por esse motivo, o comitê de acompanhamento concentra seus estudos e requerimentos de informações no âmbito do ministério. O trabalho do comitê inicia-se com os estudos dos documentos que expressam as deliberações das conferências, que são sintetizadas. Desse modo, o comitê precisa interpretar e sintetizar as demandas.

O comitê monitora todas as conferências que já ocorreram, não somente a mais recente. As demandas são expostas numa planilha por eixos temáticos. A partir desses eixos, é preenchida a primeira coluna da tabela. Em seguida, indica-se a forma como o tema foi abordado: se amplamente, medianamente ou se não foi abordado - esse último caso é para quando a demanda é considerada relevante para o comitê, embora não conste diretamente nas deliberações da conferência. A terceira coluna é preenchida com a meta anual de ações a serem efetuadas e índices a alcançar em cada eixo. Em seguida, são elencados os questionamentos e considerações do comitê em relação à implementação e ao andamento dos trabalhos ligados àquelas metas. Esses questionamentos são direcionados aos gestores responsáveis por executar as ações. 
Nas linhas referentes à quinta coluna, deverão constar as informações e indicadores do que já foi executado em relação às metas determinadas. Ainda há um espaço disponível para indicar as metas não contempladas. As duas últimas colunas são preenchidas após apresentação da tabela à plenária do Conape, pois nelas devem constar as sugestões e comentários da plenária ao que foi apresentado e a síntese dos questionamentos após discussão das informações levadas à plenária pelo comitê de acompanhamento e cumprimento das conferências. A planilha utilizada pelo comitê pode ser visualizada no Quadro 2.

\section{Quadro 2: Planilha do comitê de acompanhamento e cumprimento das conferências}

\begin{tabular}{|c|c|c|c|c|c|c|c|}
\hline $\begin{array}{c}\text { Eixo } \\
\text { temático }\end{array}$ & $\begin{array}{c}\text { Abordado } \\
\text { nas confe- } \\
\text { rências }\end{array}$ & Metas & $\begin{array}{l}\text { Conside- } \\
\text { rações do } \\
\text { comitê }\end{array}$ & $\begin{array}{c}\% \\
\text { execu- } \\
\text { tado }\end{array}$ & $\begin{array}{l}\text { Metas } \\
\text { não } \\
\text { contem- } \\
\text { pladas }\end{array}$ & $\begin{array}{l}\text { Sugestões } \\
\text { e comen- } \\
\text { tários da } \\
\text { plenária }\end{array}$ & $\begin{array}{c}\text { Sistemati- } \\
\text { zação dos } \\
\text { questiona- } \\
\text { mentos }\end{array}$ \\
\hline $\begin{array}{l}\text { Exposição } \\
\text { das } \\
\text { demandas }\end{array}$ & $\begin{array}{l}\text { Forma } \\
\text { como o } \\
\text { tema foi } \\
\text { abordado: } \\
\text { amplamen- } \\
\text { te, media- } \\
\text { namente } \\
\text { ou não } \\
\text { abordado }\end{array}$ & $\begin{array}{l}\text { Meta } \\
\text { anual } \\
\text { de } \\
\text { ações a } \\
\text { serem } \\
\text { efetua- } \\
\text { das }\end{array}$ & $\begin{array}{l}\text { Considera- } \\
\text { ções em } \\
\text { relação } \\
\text { à imple- } \\
\text { mentação } \\
\text { e ao anda- } \\
\text { mento dos } \\
\text { trabalhos } \\
\text { ligados } \\
\text { àquelas } \\
\text { metas }\end{array}$ & $\begin{array}{l}\text { Informa- } \\
\text { ções e } \\
\text { indica- } \\
\text { dores do } \\
\text { que já } \\
\text { foi exe- } \\
\text { cutado }\end{array}$ & $\begin{array}{l}\text { Espaço } \\
\text { disponí- } \\
\text { vel para } \\
\text { indicar as } \\
\text { metas que } \\
\text { não foram } \\
\text { alcançadas }\end{array}$ & $\begin{array}{l}\text { Conside- } \\
\text { rações do } \\
\text { Conape }\end{array}$ & $\begin{array}{l}\text { Síntese das } \\
\text { discussões }\end{array}$ \\
\hline
\end{tabular}

Fonte: Ipea (2013b)

Dessa forma, após realizar os estudos necessários ao preenchimento da planilha de monitoramento, discuti-la na reunião ordinária do Conape e consolidar o documento, esse é enviado à Secretaria Executiva do ministério. Em seguida, as considerações, questionamentos e demandas constantes na planilha são encaminhados aos respectivos secretários dos setores responsáveis por cada eixo temático dentro do MPA. Esses devem, por sua vez, prestar as informações que lhes forem solicitadas para que constem na próxima planilha e sejam analisadas pelo conselho. $\mathrm{O}$ trabalho de monitoramento das deliberações de conferências na área de aquicultura e pesca trata somente das ações executadas pelo MPA, não envolve, até o momento desta pesquisa, articulação com outros órgãos.

O Conselho de Aquicultura e Pesca, propondo-se a realizar o monitoramento das deliberações de sua conferência, tem como principal desafio a interlocução dentro do próprio ministério. Como a maioria das demandas surgidas na conferência tem 
como destinatário o MPA, o Conape trabalha no sentido de fomentar o diálogo interno, a fim de obter as informações necessárias ao acompanhamento desses resultados.

\section{Considerações finais}

Considerando um modelo cíclico de conferência, o monitoramento se conecta com o encaminhamento e com a accountability. Ele trabalha para que as demandas das conferências cheguem ao governo, aos seus órgãos responsáveis e, ao mesmo tempo, levanta informações sobre o que acontece ou deixa de acontecer com as deliberações das conferências.

O estudo das quatro experiências nos permite perceber que existe um trabalho, ainda em fase inicial e experimental, direcionado para o fortalecimento das práticas participativas, dos retornos do governo e do controle social. Porém, pelo fato de as práticas de monitoramento ainda estarem em fase inicial, muitos pontos ainda precisam ser aprimorados.

As próprias atividades de monitoramento fazem com que os atores envolvidos percebam a importância da prática e queiram criar mecanismos para o aprimoramento dessas atividades. Porém, em todos os casos, dificuldades são encontradas nos processos de garantia de implementação das deliberações, tais como a dificuldade de sensibilizar órgãos executores, a descontinuidade entre as edições das conferências e as práticas de monitoramento, bem como a própria imaturidade do fenômeno. No caso do monitoramento das propostas das conferências da juventude e da pesca, percebe-se que os esforços ainda estão concentrados na articulação para o monitoramento. No caso da assistência social, a principal dificuldade está relacionada à inexistência de uma metodologia sistemática, à diversidade das experiências e à desconexão entre elas.

No caso da conferência de políticas para as mulheres, a transversalidade da política exige esforços e rearranjos das atividades de monitoramento. Um dos maiores desafios enfrentados pelo comitê de monitoramento tem sido tornar os demais órgãos permeáveis à questão de gênero, uma vez que os membros do comitê não são fixos. Para solucionar essa questão, a SPM propõe a criação de comitês de gênero permanentes dentro de cada órgão federal. Além disso, as conferências de políticas para as mulheres têm sido, cada vez mais, conectadas com o planejamento, sendo o relatório final transformado em um plano de política, o qual é aprimorado nas edições seguintes, sendo priorizada a continuidade e a avaliação do plano em vigor.

Os casos estudados apontam que as conferências precisam ser compreendidas para além do evento, para dar destaque aos processos de diálogo e interação 
entre governo e sociedade. Para que esses processos tenham continuidade, o monitoramento precisa funcionar como um elo entre a realização e a preparação para a próxima edição. Seus resultados podem balizar a convocação da próxima edição: regras sobre o encontro e maneiras de formular propostas e o texto final, o conteúdo do texto base, além da possibilidade de avaliação e reflexão em relação às conferências anteriores. Entre os casos estudados, essa conexão entre edições fica mais clara na experiência da CNPM.

O monitoramento precisa acompanhar o output participativo (as propostas), seus encaminhamentos, a forma como o governo processa os resultados para o aprimoramento das políticas públicas e a adequação da agenda governamental. Assim, o monitoramento impulsionará os mecanismos de accountability, e fomentará o encaminhamento das propostas, ao cobrar posicionamento do governo e usar o feedback governamental como output para diálogos futuros, sobretudo novas edições da conferência.

Por fim, cabe ressaltar também que as conferências precisam se vincular a instrumentos de gestão de uma política, para impulsionar o monitoramento e as conexões entre participação, planejamento e execução.

\section{Referências bibliográficas}

AVRITZER, Leonardo. Conferências nacionais: ampliando e redefinindo os padrões de participação social no Brasil. Texto para discussão 1739. Rio de Janeiro: Ipea, 2012.

COSTA, Frederico Lutosa; CASTANHAR, José Cezar. Avaliação de programas públicos: desafios conceituais e metodológicos. Revista da Administração Pública, v. 37, no 5, p. 969-92, set./out. 2003.

COTTA, Tereza Cristina. Metodologias de avaliação de programas e projetos sociais: análise de resultados e impacto. Revista do Serviço Público, Brasília, v. 49, no 2, p. 103-124, abr./jun. 1998.

GASPARINI, Max Felipe Vianna; FURTADO, Juarez Pereira. Avaliação de programas e serviços sociais no Brasil: uma análise das práticas no contexto atual. Serv. Soc. Soc., São Paulo, no 117, mar. 2014.

IPEA. Ampliação da participação na gestão pública - uma estudo sobre as conferências realizadas entre 2003 e 2011. Relatório de pesquisa. Brasília: Ipea, 2013a.

Experiência de monitoramento dos resultados de conferências nacionais. Nota técnica no 7. Brasília: Ipea, 2013b.

ORTEgón, Edgar; PACHeCo, Juan Francisco; Prieto, Adriana. Metodología del marco lógico para la planificación, el seguimento y la evaluación de proyectos y programas. Santiago: Instituto Latinoamericano y del Caribe de Planificación Económica y Social (Ilpes), 2005. 
PIRES, Roberto; VAZ, Alexander. Participação social como método de governo? Um mapeamento das "interfaces socioestatais" nos programas federais. Texto para Discussão no 1707. Brasília: Ipea, 2012.

SouzA, Clóvis.; CRuXÊN, Isadora.; LIMA, Paula.; AlenCAR, Joana.; RIBEIRO, Uriella. Conferências típicas e atípicas: um esforço de caracterização do fenômeno político. In: AVRITZER, L.; SouzA, C. H. L. Conferências nacionais: atores, dinâmicas participativas e efetividade. Brasília: Ipea, 2013.

Uriella Coelho Ribeiro

Mestre em Ciência Política pela Universidade Federal de Minas Gerais (UFMG). Contato: uriellacoelho@hotmail.com Joana Luiza Oliveira Alencar

Instituto de Pesquisa Econômica Aplicada - Ipea. Contato: joana.alencar@ipea.gov.br

Paula Pompeu Fiuza Lima

Doutoranda pela Universidade de Brasília (UnB). Contato: paulapompeu@gmail.com

Clóvis Henrique Leite de Souza

Doutoranda pela Universidade de Brasília (UnB). Contato: clovis@participacao.net

Isadora Araujo Cruxên

Mestranda pelo Massachusetts Institute of Technology (MIT). Contato: isa.cruxen@gmail.com 